\title{
Taxonomies of trust in supply chain risk management in the South African third party logistics industry
}

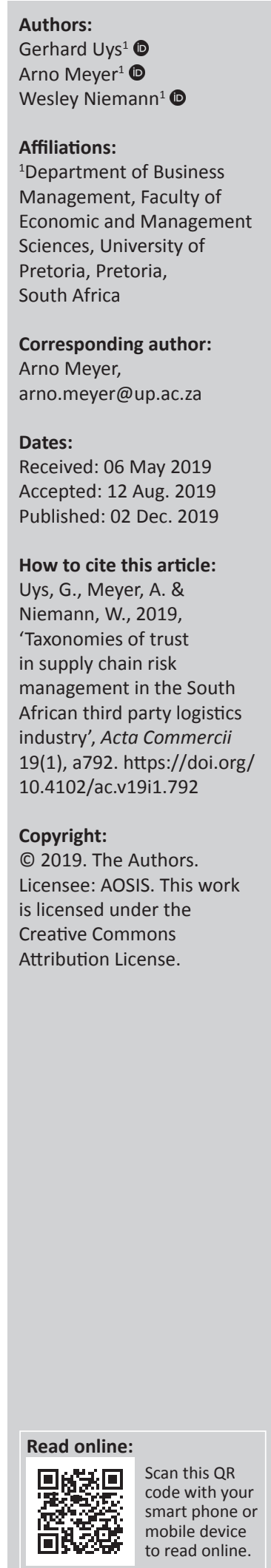

Orientation: Many organisations find it difficult to implement supply chain risk management (SCRM) processes successfully without the existence of trust in buyer-supplier relationships.

Research purpose: The purpose of this study was to explore the taxonomies of trust in SCRM in a buyer-supplier relationship within the South African third party logistics (3PL) industry.

Motivation for the study: The advantages and disadvantages of trust in buyer-supplier relationships have been researched extensively. However, within the context of South Africa, there is a dearth of research on the main components of trust in buyer-supplier relationships when implementing SCRM processes.

Research design, approach and method: A generic qualitative research method was used to gather data. A total of 21 purposively selected senior managers were interviewed from buyer and supplier organisations in South Africa with headquarters located in Gauteng province participated in semi-structured interviews. Within this sample, 10 buyer and 10 supplier organisations were interviewed.

Main findings: The findings of this study indicate that value similarity improves SCRM processes by relationship building, transparency, information sharing and similar supply chain objectives. Past performance improves SCRM processes by increasing the business knowledge of supply chain partners, confidence in ability and goal congruity. Risk perceptions improve SCRM processes by supply chain partner alignment and similar intentions. Social trust improves SCRM processes by increasing the responsiveness, agility and communication of supply chain partners.

Practical/managerial implications: This study provides practitioners in the 3PL industry with insights into the role of having trust in their buyer-supplier relationships, as trust acts as a catalyst and enabler when implementing effective SCRM processes.

Contribution/value-add: The theoretical contribution of this study is the use and adoption of the Trust Confidence and Cooperation Model by Earle, Siegrist and Gutscher (2010), to create a taxonomy of trust within a SCRM and South African 3PL context.

Keywords: SCRM; trust; buyer-supplier relationships; 3PL industry; generic qualitative research; South Africa.

\section{Introduction}

Warren Buffet stated that 'Risk comes from not knowing which cog in your supply chain is in trouble'. Supply chain risk management (SCRM) can be seen as a strategic process used by organisations to mitigate the impact that supply chain risks (SCRs) have upon the supply chain (Kwak et al. 2018:373; Nooraie \& Parast 2015:192). Supply chain risks are considered risks that can negatively affect any part of the supply chain and that hinder the organisation in the accomplishment of its desired ideals of efficiency and effectiveness (Ho et al. 2015:5035; Prakash, Soni \& Rathore 2017:130). To successfully implement SCRM, buyers and suppliers must work together to jointly address SCRs (Wandfluh, Hofmann \& Schoensleben 2016:201).

The necessity for organisations to establish supply chain relationships and the value thereof is well recognised in current literature (Gligor \& Holcomb 2013:329; Mocke, Niemann \& Kotzé 2016:2). Benefits of buyer-supplier relationships include greater customer satisfaction, better market and operational performance, a rise in customer referrals and higher levels of partner commitment and trust (Meyer, Niemann \& Kotzé 2017:1; Villena, Revilla \& Choi 2011:562). Trust in general between a buyer-supplier relationship can be defined as 'perceived competence, objectivity, fairness, consistency, goodwill, confidence and the prediction that others will act supportively rather than exploitatively' (Van Riper et al. 2016:25). This can be explained as the certainty that one party will not misuse the welfare of the other party (Van Riper et al. 2016:25). 
One of the main aspects that add to SCRs is the lack of trust in a buyer-supplier relationship, which results in less collaborative operations (Gligor \& Esmark 2015:518; Yang 2014:106)

Trust matures with constant and recurring interactions between the buyer and the supplier, resulting in a long-term relationship between the two parties (Ghadge et al. 2017:264). The advantages and disadvantages of trust in a buyersupplier relationship have been the subject of considerable research (Fan \& Stevenson 2018:20; Prakash et al. 2017:77). However, creating a broader understanding of trust beyond mere advantages and disadvantages has received less attention in extant research. This study aims to focus upon an expansive understanding of elements within trust that enable effective and efficient SCRM processes, which will henceforth be referred to 'taxonomies of trust'. Taxonomies of trust can be described as exploring multiple constructs pertaining to trust within SCRM (Earle et al. 2010:27).

Within the Trust Confidence and Cooperation (TCC) Model, a simplified model of the direct relationship between risk and trust specifically is presented (Earle et al. 2010:27). The key constructs mentioned in this model are value similarity, past performance, social trust and risk perception. Further research is required to create a deeper and holistic understanding of the various taxonomies of trust in SCRM in a buyer-supplier relationship, so as to contribute theoretically and practically to the field of supply chain management and to provide tangible and intangible elements that are not limited to advantages and disadvantages ( $\mathrm{Li}$ et al. 2015:86; Prakash et al. 2017:77).

A typical example of a buyer-supplier relationship is the relationship between a third party logistics (3PL) service provider and its clients. A 3PL provider is an external organisation that provides a range of logistical services on behalf of their clients (Akman \& Baynal 2014:3). Third party logistics performed a relational role that focuses on a partnership for strategic advantage (Jayaram \& Tan 2010:264). In addition, 3PLs also act as a customer developer or logistics integrator where the internal resources might be lacking within an organisation (Niemann et al. 2018:1745). The taxonomies of trust in SCRM between buyers and suppliers in a $3 \mathrm{PL}$ industry within a developing country context entail a considerable knowledge gap as the role of 3PLs is changing into a value-adding and orchestrating role within developing countries (König \& Spinler 2016:123; Macdonald \& Corsi 2013:285) because of their engagement with an organisation's suppliers and customers (Heiyantuduwa, Wannisingha \& Rupasinghe 2015:2). Furthermore, organisations make use of 3PL providers to focus upon their core competencies. Thus, 3PL providers are strategically important for when SCRs arise in the supply chain (König \& Spinler 2016:123). In order for organisations to move towards successful SCRM, a stable trust relationship should exist between the 3PL organisation and the buyer organisation (Friday et al. 2018:231). The following research questions guided the study:
- What role does value similarity have in SCRM in a buyersupplier relationship?

- How does past performance shape SCRM within a buyersupplier relationship?

- What role does supply chain parties' perception of risk have in SCRM within a buyer-supplier relationship?

- How does social trust in a buyer-supplier relationship improve SCRM?

The study contributes from a theoretical perspective on trust in SCRM by using a well-established consensus model of trust (the TCC Model), which has predominantly mostly been used in the disciplines of social psychology and organisational trust in previous research. By exploring the taxonomies of trust through the lens of this consensus model, and the role which these constructs have in enhancing trust in SCRM, it may also provide insights into other recurrent issues such as trust asymmetry between buyers and suppliers, as well as the relationship between trust and impartiality (Prakash et al. 2017:77). The managerial contribution is to be able to determine which of these concepts should be prioritised and better managed, so as to enhance trust in SCRM between buyer-supplier relationships.

This article is structured as follows: the first section offers an extensive review of literature pertaining to the main topics of the study. This is followed by a discussion of the study's research design, sampling and data collection and analysis. The next section presents the research findings, followed by the conclusion, which compares the findings to the existing literature. Subsequently, the theoretical implications, managerial recommendations, the limitations of the present study and recommendations for future research are discussed.

\section{Literature review}

\section{Supply chain risk management}

Jüttner (2005:124) defines SCRM as the identification and management of risk for the supply chain, through a coordinated approach among supply chain members, to reduce supply chain vulnerability as a whole'. The main goal of SCRM is to reduce vulnerability and costs, leading to potential long-term profitability and growth (Kilubi \& Haasis 2015:40). These benefits can only be acquired if successful collaboration and synchronisation between the various partners in the supply chain are evident (Sahu, Datta \& Mahapatra 2017:121). One way in which organisations can create value is to have the entire supply chain network make use of the four-step SCRM process, to mitigate SCRs (Rashid, Loke \& Ooi 2014:296).

The first step in the SCRM process is the identification of the relevant SCRs that the organisation faces (Fan et al. 2017:63). In the process of identifying the SCRs, it is crucial to consider the relevance of the SCRs to the organisation (Fan \& Stevenson 2018:9). The SCRM identification process involves, among others, the listing of possible SCRs, the prioritising of SCRs and the categorising of SCRs (Kwak et al. 2018:373). The second step in the SCRM process is the assessment of the relevant 
SCRs (Simba et al. 2017:3). In this step of the SCRM process, two major characteristics of each risk should be anticipated when assessing the SCR (Dong \& Cooper 2016:145). The first characteristic to consider is the possible impact that the SCR will have upon the organisation (Bühler, Wallenburg \& Wieland 2016:704). The second characteristic is the probability (likelihood) of the SCR occurring (Moore et al. 2015:15).

The third step of the SCRM process entails the mitigation of the relevant SCRs (Prakash et al. 2017:84). There are various ways in which organisations can handle risks, including risk transference, risk acceptance, risk sharing and risk avoidance (Fan \& Stevenson 2018:13). Organisations select the most appropriate mitigation strategies according to the likelihood and significance of the SCRs while also considering the available resources (Chang, Ellinger \& Blackhurst 2015:645). Lastly, the final step in the SCRM process is the monitoring of the SCRs (Elleuch, Hachicha \& Chabchoub 2014:642). It is of the utmost importance for organisations to unremittingly revise the SCRs, to ensure value creation of the SCRM process (Charkhab, Eslami \& Dehnavi 2014:418). Risk monitoring is a pivotal step in the SCRM process.

\section{Third party logistics}

Organisations outsource their logistics activities to competent 3PL organisations, so as to control and manage this important function in the supply chain (Alkhatib, Darlington \& Nguyen 2015:102). Logistics services include distribution, manufacturing services, financial services, transportation, warehousing, reverse logistics and information-related services (Coyle et al. 2017:495). According to the annual Agility Emerging Markets Logistics Index of 2019, South Africa is ranked as the 11th fastest growing logistics market of the 50 developing countries within the surveyed index. Globally, within this market, organisations rely upon the skills and implied knowledge of the logistical network of 3PL service providers, to provide them with a number of economic and operational benefits (Zhu et al. 2017:32).

The significant contribution to the South African Gross Domestic Product (GDP) and employment of the 3PL industry in South Africa is also clearly evident. In 2016, logistical costs contributed R499 billion to the South African GDP (Armstrong \& Associates 2017). This accounted for approximately $11.8 \%$ of South Africa's GDP in 2016 (University of Stellenbosch 2016:5). Within South Africa, the majority of logistic services are provided through the transportation of goods. Organisations that make use of 3PL providers have seen a reduction in costs and an increase in customer satisfaction (Coyle et al. 2017:495). However, organisations can only take full advantage of outsourcing logistical activities through having a solid relationship and trust between buyers and their 3PL provider (D'Amato et al. 2015:2).

The main advantage of having a well-functioning, sophisticated buyer-supplier relationship is the increased efficiency that will be noticeable in the operations of both parties (Nyaga, Whipple \& Lynch 2010:101). In addition, another important advantage includes the trust that stems from robust relationships (Wieland \& Wallenburg 2013:316). Well-established trust in a buyer-supplier relationship enables organisations to create ways of reducing complexities and SCRs (Li et al. 2015:86). The motive behind trust-reducing SCRs and complexities is that supply chain members can anticipate possible behaviours of supply chain partners (Chung et al. 2016:70).

\section{Buyer-supplier relationships}

A formal buyer-supplier relationship is defined by the mutual commitment derived from both members (Huo et al. 2017:928). Buyer-supplier relationships are further defined as where one organisation acts as the supplier of a certain product or service and the other party purchases the product or service (Maestrini et al. 2018:3). Buyer-supplier relationships are formed with the intention of generating strategic objectives for each member contributing towards the success and longevity of the relationship (Barnes et al. 2015:27). Various tenets of a buyer-supplier relationship exist, which include information sharing, collaboration, cultural alignment and risks that are shared between the two organisations (Barnes et al. 2015:27).

Information sharing can be defined as the exchange of valuable information, such as demand forecast, point-of-sale data, product mix and inventory level between organisations in the supply chain network (Handfield et al. 2015:7). Previous research suggests that information sharing is invaluable for successful supply chain management and SCRM because it fosters flexibility, cohesion and responsiveness in the relationship (Fan et al. 2017:65). The implementation of continuous information sharing between members in a buyer-supplier relationship will enable the successful implementation of SCRM (Riley et al. 2016:957).

Collaboration is defined as the organisations in the supply chain working together to produce an intended improved result (Wang et al. 2016:838). Collaboration is required from both organisations in a relationship to improve supply chain performance (Wu, Chuang \& Hsu 2014:129). Organisational attitude towards collaboration can be directly linked to the long-term benefit that they received from such earlier or existing relationships (Soosay \& Hyland 2015:625). If an organisation's past experiences of long-term relationships are positive and lucrative, then their approach to building a long-term relationship in the future will be optimistic (Ramanathan \& Gunasekaran 2014:258).

Buyer-supplier relationships can be influenced by various factors, one of these factors being the culture of both organisations (Barnes et al. 2015:27). There needs to be an alignment of the cultures and values of the two organisations so as to create a long-lasting relationship (Spence et al. 2018:143). A buyer-supplier relationship is an area that needs constant attention to maintain and even improve upon the benefits achieved (Kumar Sharma \& Bhat 2014:1025). The presence of risk sharing in a relationship can have significant 
advantages for a supply chain network (Ghadge et al. 2017:264). Risk sharing can be regarded as a SCRM enabler, and if SCRM is implemented properly, it may even result in a competitive advantage (Brandon-Jones et al. 2014:58). When members in a buyer-supplier relationship embrace a risk sharing approach successfully, the meaningful increase in responsibility of resolving SCRs is apparent (Li et al. 2015:86).

\section{Trust, confidence and cooperation model}

Trust is an abstract and dichotomous concept to manage, as trust is accumulated over a sustained period of continuous and multiple interactions, contrasted to the fact that it can also be extirpated instantaneously by a single negative interaction (Tejpal, Garg \& Sachdeva 2013:52). The best way to address this complex and contextual phenomenon is to make use of a sound model that is based upon extant literature (Capaldo \& Giannoccaro 2015:36). The TCC Model is originally based upon the work of Slovic (1993:676), who states that in resolving any conflict having trust between the two parties is more important than the risk in itself (Slovic 1993:676). The TCC Model fills the role of a uniform framework of trust which can act as a base for future research (Earle et al. 2010:27). Trust and risks are inter-related, and if there is no trust present, then there will most probably be an increased risk (Ojha, Shockley \& Acharya 2016:214). The model adapted from the TCC Model of Earle et al. (2010:27) within a SCRM context focuses upon four distinctive, yet very inter-related concepts. These concepts are value similarity, past performance, risk perception and social trust.

For any relationship to be successful, intentions from both parties should be similar (Spence et al. 2018:143). The intentions should be perceived as organisations focusing on achieving the same outcomes (Thomas et al. 2018:194). The value similarity applicable to the study is the manner in which the organisation conducts business. Employees tend to shape the values of the organisation; thus, the values of the employees influence the values of the organisation (Trkman, Oliveira \& McCormack 2016:1075). Organisations can have either a proactive or a reactive approach towards SCRM (Grötsch, Blome \& Schleper 2013:2842). Trust between a buyer and a supplier can be damaged beyond repair if certain discussions regarding SCRM, such as their relevant approaches to SCRM, are not known to each other nor discussed (Chen, Chen \& Wu 2017:459). Two of the most important values that need to be visible in a successful buyersupplier relationship are openness and honesty (Cho, Ryoo \& Kim 2017:185). When there is dishonesty from one of the two organisations, and the other one suspects it or finds out about it, the trust is automatically diminished (Lord et al. 2017:486).

Past performance is the record of accomplishment of the organisation's performance over a period of time (Wang, Craighead \& Li 2014:377). Past performance plays a distinctive role in establishing the willingness of the other organisation to conduct business with the focal organisation (Wang et al. 2014:377). How an organisation has dealt with past SCRs can be a key indicator to the other organisation if they want to start a relationship with this organisation (Li, De Souza \& Goh 2016:307). Past performance influences risk perception and is influenced by social trust. The perception that organisations have of the other organisation's ability to mitigate and handle SCRs is based upon their past performance with related SCRs (Abeyratne \& Monfared 2016:2).

An organisation's perception of SCRM will have a major influence upon the organisation's ability to work with its organisational counterparts creating a multi-beneficial relationship (Kwak et al. 2018:385). The literature shows that when organisations share the same view of SCRM, they are expected to present more successful SCRM efforts (Kumar et al. 2017:433). Risk perception entails the organisations' current knowledge of the SCRs that they are facing, based upon previous experience (Ramanathan \& Gunasekaran 2014:258). Another aspect that influences risk is the morality information of social trust (Branyi, Jozsa \& Machova 2015:103). Morality information is mainly based upon organisational beliefs and value similarity. Risk perception directly influences an organisation's ability to enhance trust (Kumar et al. 2017:433). Organisations need a certain risk perception to successfully have SCRM (Revilla \& Saenz 2017:560).

Social trust can generally be defined as the overall basic trust level of individuals in humanity (Qu et al. 2015:152). From a SCRM perspective, social trust can be considered to be the trust that is built up over the years through relationships between individuals from two organisations (Yan, Zhang \& Vasilakos 2014:121). The second concept that is needed for enhancing trust in a buyer-supplier relationship is the belief of one organisation in another (mutual trust) (Ryciuk 2017:627). Trust, however, is not a pre-defined agreeable clause in the contract. Trust, as with perceptions, is not a directly measurable attribute and cannot be benchmarked (Qazi et al. 2018:26).

Organisational trust is a combination of trust relationships between individuals (Yan et al. 2014:121). Because human beings are socially interactive creatures, a strong building block of trust is the social interaction between individuals of different organisations, such as dining together, playing golf or other sport and even joint leisure activities (Meyer et al. 2017:7). Social trust is influenced only by value similarity (Earle et al. 2010:27). Figure 1 illustrates what role each of the four concepts has in enhancing trust.

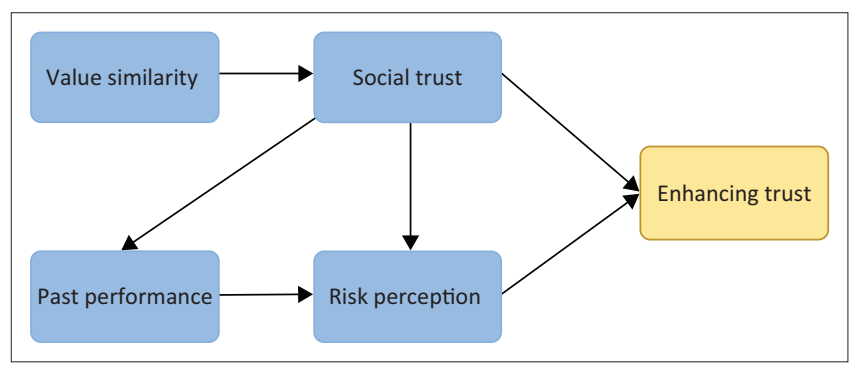

Source: Adapted from Earle, T.C., Siegrist, M. \& Gutscher, H., 2010, Trust in risk management Uncertainty and scepticism in the public mind, p. 27, Earthscan, London.

FIGURE 1: Influence of four core concepts upon enhancing trust. 


\section{Methodology}

\section{Research design}

The study applied a generic qualitative research design, which was used to illustrate the understanding of participants' opinions of a specific phenomenon at a specific time (Percy, Kostere \& Kostere 2015:78; Plano Clark \& Creswell 2015:289). According to Percy et al. (2015:78), researchers generally make use of a generic qualitative research design when there is a basic understanding of a specific topic. However, the perspectives of participants contribute to an improved description of the basic understanding of the trust element in SCRM. This understanding was required regarding the role of trust in SCRM, and this research design was, therefore, the best suited to the research problem.

\section{Sampling}

The unit of analysis for the study was buyer-supplier relationships in the South African 3PL industry and organisations that make use of 3PL services. The study made use of purposive sampling, which can be defined as the intentional selection of organisations or individuals that will make a significant contribution to the understanding of the presented phenomenon (Palinkas et al. 2015:534). Purposive sampling enabled the researchers to choose the most suitable and knowledgeable participants for inclusion in the study. The inclusion criteria for the participants were middle to senior management level with job titles such as, but not limited to, operations manager, logistics manager and supply chain executives. The participants in the study were required to have interaction with the other party of the buyer-supplier relationship and be involved in SCRM activities. In addition, the duration of the relationship between the two organisations had to be a minimum of 1 year, as this is how long it usually takes for a sound relationship to be formed (Chi, Zhao \& George 2015:1122).

The secondary sampling technique used to obtain individuals of specific organisations for the study was snowball sampling. Snowball sampling involves requesting one or more than one participant, who is information-rich, to present the researcher with contact details of other possible participants (Merriam 2009:79; Patton 2015:270; Saunders, Lewis \& Thornhill 2016:303). After interviewing participants, snowball sampling was used to identify the most suitable corresponding buyer or supplier organisations with whom to conduct additional interviews. The participant profiles are presented in Table 1.

\section{Data collection}

Data were collected through semi-structured interviews. One of the advantages of conducting semi-structured interviews is that they allow for a deeper understanding of the phenomenon under investigation (Creswell 2012:218). A discussion guide was developed from a thorough literature review, to ensure that all the research questions were addressed. A pre-test was conducted with a participant, adhering to the criteria for participation, to test the discussion guide. After conducting the pre-test, minor amendments were made. In view of the fact that no major changes were made to the discussion guide after the pre-test, the participant was included in the actual sample.

Before commencing with interviews, permission was requested from participants to audio-record the interview. The recorded interviews were transcribed by a professional transcription service. All the transcriptions were examined

TABLE 1: Participants' profiles.

\begin{tabular}{|c|c|c|c|c|c|}
\hline \multirow[t]{2}{*}{ No. } & \multicolumn{2}{|c|}{ Pseudonym } & \multirow[t]{2}{*}{ Position of participant } & \multirow[t]{2}{*}{ Relationship duration (years) } & \multirow[t]{2}{*}{ Duration of interview ( $\mathrm{min}$ ) } \\
\hline & Participant & Buyer/supplier & & & \\
\hline 1 & P1 & S1 & Warehouse Manager & 3 & 28 \\
\hline 2 & $\mathrm{P} 2$ & S1 & National Warehouse Manager & - & - \\
\hline 3 & P3 & S2 & General Manager - Supply Chain Innovation & 10 & 40 \\
\hline 4 & P4 & S3 & Business Development Executive & 15 & 43 \\
\hline 5 & P5 & S4 & Senior Business Analyst & 9 & 32 \\
\hline 6 & P6 & S5 & Managing Director & 1 & 29 \\
\hline 7 & P7 & S6 & Airfreight Director & 6 & 26 \\
\hline 8 & P8 & S7 & Chief Operating Officer & 15 & 31 \\
\hline 9 & P10 & S8 & National Customs Manager & 14 & 34 \\
\hline 10 & P11 & S9 & Business Development Director & 5 & 44 \\
\hline 11 & P15 & S10 & Warehouse Manager & 8 & 32 \\
\hline 12 & P9 & B1 & Logistics Manager & 2 & 22 \\
\hline 13 & P12 & B2 & Group Head of Logistics & 8 & 36 \\
\hline 14 & $\mathrm{P} 13$ & B3 & Supply Chain Manager & 15 & 36 \\
\hline 15 & P14 & B4 & Strategic Sourcing Manager & 6 & 43 \\
\hline 16 & P16 & B5 & Inbound Logistics Manager & 10 & 31 \\
\hline 17 & P17 & B6 & Territory Manager & 7 & 51 \\
\hline 18 & P18 & B7 & Head of Transport & 20 & 26 \\
\hline 19 & P19 & B8 & Customer Service Manager Africa & 6 & 35 \\
\hline 20 & P20 & B9 & National Risk Manager & 10 & 29 \\
\hline 21 & $\mathrm{P} 21$ & B10 & Transport Operations Manager & 15 & 22 \\
\hline Total & 21 & 20 & Average & 9 years & $34 \mathrm{~min}$ \\
\hline
\end{tabular}


and reviewed through listening to the recordings and reading the transcriptions at the same time, so as to ensure accuracy and verbatim statements of participants. The length of the interviews ranged from 22 to $51 \mathrm{~min}$ and the average length was $34 \mathrm{~min}$. A total of 21 participants from 20 different organisations participated in the study. Of the 20 organisations, 10 organisations were buyers and 10 organisations were suppliers. Data saturation was reached after interview 16. According to the literature, when three consecutive interviews do not generate any new information, data saturation may likely have been reached (Charmaz 2006:113). Four additional interviews were conducted to ensure that no new ideas or data emerged before the data collection was terminated.

\section{Data analysis}

Data was analysed according to a thematic analysis approach, which included identifying patterns and crucial topics of the collected data through in-depth analysis and reporting (Vaismoradi, Turunen \& Bondas 2013:78). The thematic analysis approach simplifies the process and flexibly offers dependable data. Transcripts were inductively classified into different categories, groups, themes and codes (Creswell 2012:236-253). Themes are defined as answers that shape a pattern, while codes are features that link to the particular study's research questions (Braun \& Clarke 2012:60). Themes and codes were generated inductively as interviews and data collection proceeded. The themes and codes were continuously reviewed and improvements were made, to ensure alignment with the research questions (Braun \& Clarke 2012:4). In addition, Atlas.ti was also used to assist in the process in analysing the data.

\section{Trustworthiness}

The criteria to ensure trustworthiness of the study include credibility, dependability, confirmability and transferability (Polit \& Beck 2012:584; Shenton 2004:64). Credibility entails that the findings of the study offer an accurate reflection of the state of the phenomenon in reality (Polit \& Beck 2012:585). Voluntary participation and the confidentiality of participants were guaranteed and the use of reliable methods such as purposive sampling and thematic analysis assisted the credibility of the study by selecting the most appropriate participants and by inductively generating new findings based upon the participants' opinions (Polit \& Beck 2012:584585; Shenton 2004:64-69). Dependability implies that the findings will be consistent and similar when the same context participants and methods are involved in a replicated study (Polit \& Beck 2012:585; Shenton 2004:71). The researchers made sure that an in-depth and detailed description of the participants, context and methodology was provided, to create a well-defined path for future attempts to replicate the study.

Confirmability refers to the objectivity of findings and the fact that they are not influenced by the researchers' own ideals or frame of reference (Shenton 2004:64). To help improve confirmability, the researchers made use of clear audit trails, to ensure that the findings are a true reflection of the participants' opinions. By making use of audio recordings, document containments and verbatim interview transcriptions, a complete audit trail of the data analysis was constructed. Transferability refers to how well the findings in the study can be used in another setting or context (Polit \& Beck 2012:585; Shenton 2004:67-71). A comprehensive explanation of the context in which the qualitative study was performed and providing the limitations of the study will assist in ensuring transferability.

\section{Ethical considerations}

The Research Ethics Committee at a traditional South African university in Gauteng approved the study prior to data collection. Each participant was required to sign a consent form before commencement of the interview, which indicated his or her willingness to be interviewed voluntarily. Participant were assured that their identity would be kept confidential. Every participant and organisation referred to throughout the interviews was given pseudonyms (Table 1). Participants were also informed that they were not obligated to answer every question and that they might terminate the interview at any given time.

University of Pretoria, Ethical Clearance Number: GU1605, Ethical Clearance was received: 2018/08/12.

\section{Findings}

Four primary themes were generated from the data, namely value similarity, past performance, risk perception and social trust. Each of these themes contains certain sub-themes, as indicated in the frequency table below (see Table 2). The themes and sub-themes were examined and supported with quotations from the participants that were compared to the literature. Table 2 presents the frequency table of the primary themes, the sub-themes and the research question related to each theme.

\section{Value similarity}

The first theme that will be discussed is value similarity between the buyer and supplier. For any relationship to be successful, intentions from both parties should be similar (Spence et al. 2018:143). The intentions should be perceived as organisations focusing on achieving the same outcomes (Thomas et al. 2018:194). The role of value similarity in SCRM in a buyer-supplier relationship can be categorised into four distinctive sub-themes. Firstly, through relationship building by having the same values between a buyer and a supplier, organisations help to develop and establish a long-standing relationship, thereby improving SCRM. Eleven of the 21 participants indicated that sharing the same values helps to build better relationships with their supply chain partners. This aligns with the literature, which indicates that relationships are supported when similar values are held by 


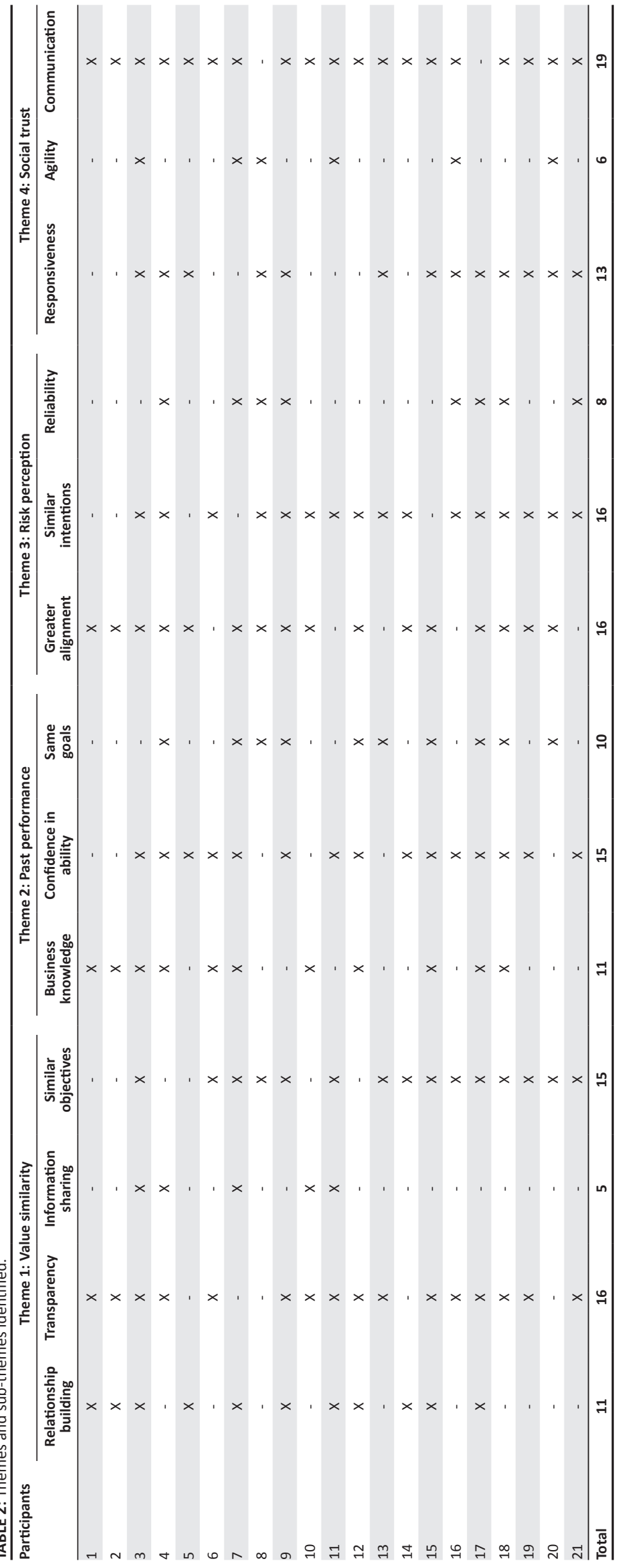


both organisations (Cho et al. 2017:185). This is evident in the quotes below:

'So if your values are complementary, or the same, your ability to work together or to be a friend is just so much easier.' (P14, B4, Female, Strategic Sourcing Manager)

'To mitigate risks quicker and better to kind of eradicate the finger pointing, when things don't go right because we work in operations. So you plan for everything to go right. But often things don't go right because things change. So it's a much more mature relationship if you share similar values.' (P15, S10, Female, Campus Manager)

Secondly, organisations that share the same values will attempt to have transparency, specifically openness and honesty between them and their supply chain partner. This ensures that true and correct information is shared, which improves SCRM. Sixteen of the 21 participants indicated that having the same values helps to enforce openness and honesty in the buyer-supplier relationship. This supports current literature, which states that openness and honesty are instrumental in forming a buyer-supplier relationship (Cho et al. 2017:185). The quotes below saliently illustrate this point:

'Your customer has to trust you, and the only way your customer trusts you is by being transparent with them and being accountable.' (P6, S5, Male, Managing Director)

'For sure the typical relationship is built upon honesty and trust, so we need to be very open and honest with each other about our businesses, particularly those that are smaller than us.' (P18, B7, Male, Head of Transport)

Thirdly, value similarity plays a role in SCRM through information sharing. Having similar organisational values helps to develop trust and improve SCRM, which is required in order for information sharing to be apparent in a buyersupplier relationship. Five of the 21 participants indicated that information sharing is one of the constructs of value similarity, which plays a role in SCRM between a buyer and supplier organisation. This finding supports literature in stating that information sharing that is false can cause more damage than not sharing information at all (Handfield et al. 2015:7). Refer to the exemplary quotes below:

\footnotetext{
'That also speaks to trust. So when something goes wrong, it's a lot easier to speak to somebody where you have a good relationship and where there is trust. Where there is a lack of trust, there is a lack of integrity and honesty.' (P7, S6, Male, Airfreight Director)

'Yes, because if we don't have trust, if we don't have the same values, if we don't see ourselves as partners, are you really going to share information or are you just a service provider and that's it.' (P11, S9, Male, Business Development Director)
}

Lastly, organisations with similar values find it easier to work towards a unified objective, which improves the collaboration in terms of addressing SCRs. Collaboration is of the utmost importance in order for both organisations to successfully improve SCRM (Wu et al. 2014:129). Fifteen of the 21 participants indicated that similar objectives are a way in which value similarity plays a role in SCRM. This finding corroborates statements reflected in the literature, in that organisations that share the same values tend to work towards similar, unified objectives (Soosay \& Hyland 2015:625). This is evident in the quotes below:

'Absolutely, I would say that the more that these values and goals and everything is aligned, the better the relationship is actually going to work. The less it's aligned, the more there is going to be friction and clashes, and it's going to be difficult to make that relationship work.' (P3, S2, Male, General Manager)

'Look, if the values are different, the problem is that there will not be a common goal that needs to be achieved. Then going about business there cannot be business continuity if there are issues with the values.' (P9, B1, Male, Logistics Manager)

\section{Past performance}

Past performance is defined as the track record of the organisation's performance over a period of time (Wang et al. 2014:377). The past performance of organisations in their operations, specifically in SCRM, plays a significant role in the buyer-supplier relationships (Abeyratne \& Monfared 2016:2). The way in which organisations have dealt with SCRs in the past is a key determinant for organisations to decide upon doing business with a new organisation or not (Wang et al. 2014:377). How past performance shapes SCRM in a buyer-supplier relationship is divided into three subthemes, namely business knowledge, confidence in ability and same goals.

Firstly, when the past performance in SCRM of an organisation is known, the supply chain partner is much more receptive to discuss future SCRM initiatives. Organisations want to know that their supply chain partner has integrated knowledge of their business before partnering with them. Eleven of the 21 participants indicated that business knowledge is a way in which past performance shapes SCRM in a buyer-supplier relationship. This finding is in line with the literature in indicating that business knowledge helps to shape SCRM and the buyer-supplier relationships (Hudnurkar, Rathod \& Jakhar 2016:626). The quotes below clearly illustrate this point:

'We not only look at their presentation and the survivability of their BCP [business continuity plan] or risk plan, we also go and meet up. If we can, we go and view certainly their premises and also their customers. We engage with them and interview them around their past history and what their views are in working with that new vendor, just to get a feel.' (P18, B7, Male, Head of Transport)

'Yeah, it obviously goes a long way. It goes without saying that a lot of our customers through the risk mitigation environments appreciate the coexistence with us, that strongly built relationship which has given us 10 years in our contracting.' (P4, S3, Male, Business Development Executive)

The second sub-theme of past performance that shapes SCRM in a buyer-supplier relationship is the confidence in ability. The past performance in SCRM of an organisation indicates the organisation's ability to mitigate SCRs successfully or not. This is key to establish trust in the 
relationship and ultimately to improve SCRM. Fifteen of the 21 participants indicated that the past performance in SCRM of the buyer or supplier organisations shapes SCRM in the buyer-supplier relationship. This adds to the literature in stating that not only does the past performance of SCRM play a role in the willingness to collaborate, it also plays a direct role in the successful implementation of SCRM (Wang et al. 2014:377). Refer to the exemplary quotes below:

'But trust is something that's going to be developed, you need to basically have a proven track record to say that you've done it for a couple of months or a couple of years and the guys can really see that you're actually doing what you promised and not just selling them something.' (P3, S2, Male, General Manager)

'And since then, it's probably been eight years just as a result of that. That client has never asked us for anything more, anything out of the ordinary. They knew that we would contain that risk and manage it, so that has been a feather in our cap as well.' (P4, S3, Male, Business Development Executive)

'Due to the past experiences that we have seen in their history, a situation has been created whereby we are very comfortable. And the trust has just grown from there.' (P9, B1, Male, Logistics Manager)

Having the same goals constitutes the third sub-theme of past performance, which shapes SCRM in a buyer-supplier relationship. The past performance concerning SCRM indicates the intentions or attitude of organisations towards SCRM. Organisations that share the same intentions or attitude towards SCRM tend to implement SCRM more successfully. Ten of the 21 participants indicated that the past performance in SCRM of an organisation is a key indicator of their tendency to work towards a unified goal. This supports the literature in stating that the same end-objective needs to be evident on both sides of the relationship, to successfully implement SCRM (Ramanathan \& Gunasekaran 2014:258). This is evident from the quotes below:

'Your question was, has our historic experience, our historic experience with them, formed our mutual approach to risk in the future? And we have not had any disagreements.' (P8, S7, Male, Chief Operating Officer)

'Also, from the O8 international perspective, we have used O8 international as a benchmark to see whether O5's past performances would be able to support our strategic objective. And they did.' (P9, B1, Male, Logistics Manager).

\section{Risk perception}

The literature posits that when organisations share the same view of SCRM, they are expected to present more successful SCRM efforts (Kumar et al. 2017:433). In addition, risk perception entails the organisation's current knowledge of the SCRs that they are facing, based upon previous experience (Ramanathan \& Gunasekaran 2014:258). An organisation's perception of risk can have a major influence on the SCRM that is conducted in a buyer-supplier relationship (Kwak et al. 2018:385). The perception of risk of supply chain parties plays a role in SCRM through three distinctive constructs, namely greater alignment, similar intentions and reliability. Firstly, greater alignment, which plays a role in risk perception, is one of the constructs that was identified by the participants. Organisations sharing the same perception towards SCRs implement SCRM more successfully. This is because of better alignment of end goals and what is required to mitigate the SCRs. Sixteen of the 21 participants indicated that greater alignment was one of the ways in which risk perceptions played a role in SCRM in a buyer-supplier relationship. This substantiates the literature in stating that an organisation cannot implement SCRM alone and needs supply chain partners who share the same aligned perception of SCRs (Kwak et al. 2018:373). The quotes below illustrate this point:

'So those two things, are very similar and have very similar approaches in terms of what we believe and which risks are reasonable and unreasonable.' (P8, S7, Male, Chief Operating Officer)

'I think our attitude is very much aligned. They specifically understand our product, and they understand the inherent risks of moving it.' (P12, B2, Male, Group Head of Logistics)

The second way in which risk perception plays a role in SCRM is through similar intentions. Organisations tend to implement SCRM more effectively because of having similar risk perceptions. Supply chain risks are classified and addressed in the same manner because of the intentional alignment of risk perceptions. This enriches collaboration, which enhances SCRM. Sixteen of the 21 participants specified that similar intentions are one of the ways in which risk perception plays a role in SCRM in a buyer-supplier relationship. This finding substantiates the literature in affirming that organisations that share the same view of SCRM tend to offer more successful SCRM efforts (Kumar et al. 2017:433). Refer to the exemplary quotes below:

'The relationship is integral, the trust is integral. I don't think we would get the legs and the length of our investments and what we have done if it was just one sided.' (P4, S3, Male, Business Development Executive)

'That is the key reason why we formed a partnership. Because of the fundamental risk identification, risk mitigation and risk containment. That was the backbone of forming the partnership with S5 and ourselves.' (P9, B1, Male, Logistics Manager)

Lastly, reliability is indicated as the third way in which risk perception plays a role in SCRM in a buyer-supplier relationship. Organisations comprehend that their supply chain partner takes into consideration their own business well-being when making decisions. This is because of the alignment of risk perceptions. Supply chain risk management is implemented more successfully when the intentions of both organisations are reliable, true and aligned (Kwak et al. 2018:373). Eight of the 21 participants indicated that reliability is one of the ways in which risk perceptions play a role in SCRM in a buyer-supplier relationship. This adds to the literature in stating that having the same aligned perception towards SCRs helps to create reliability in the buyer-supplier relationship, which, in turn, aids in the successful implementation of SCRM. See the supporting quotes below:

'I would say so, and I would say that it's something that we certainly take very seriously when we look at supply chain partners. It is guys who take our business seriously for one, but 
also that are hands-on in understanding what the challenges are and then of when they occur and getting the results.' (P17, B6, Male, Territory Manager)

'It certainly helps you kind of have a comfort feel. As I said, in the last month, we had discussions about wage negotiations in the industry. We were quite comfortable that we didn't have to ask them to get plans in place to potentially mitigate a strike if it ever happened.' (P18, B7, Male, Head of Transport)

\section{Social trust}

Social trust is divided into two characteristics. The first is the overall basic trust level of individuals in humanity (Qu et al. 2015:152). This is the initial trust an organisation has in another organisation (Yan et al. 2014:121). The second is the personal relationships that develop between the buyer and supplier organisations (Ryciuk 2017:627). For social trust to play a role in enhancing trust or SCRM, either one of the two characteristics of social trust can be present. Responsiveness, agility and communication were identified as the three ways in which social trust improves SCRM in a buyer-supplier relationship. Firstly, a buyer-supplier relationship where social trust is evident presents a faster and more effective reaction to SCRM. The responsiveness between the buyer and supplier is aided by having that social trust in the relationship. Various formal processes and formalities can be moved aside, to be more responsive in the mitigation of SCRs. Thirteen of the 21 participants indicated that responsiveness is one way in which social trust assists to improve SCRM in a buyer-supplier relationship. This supports the literature in stating that because of social trust, organisations can respond more promptly to SCRs in a buyer-supplier relationship. This is clear from the quotes below:

'Look I think that if anything needs to be done, if you have a good relationship you are going to get it done probably more efficiently and more effectively.' (P13, B3, Female, Supply Chain Manager)

'We pick up the phone and speak to senior management, and they are here within 10-15 minutes. We get it resolved, and we move on.' (P19, B8, Male, Customer Service Manager)

The second way in which social trust improves SCRM in a buyer-supplier relationship is through agility. Having social trust present in a buyer-supplier relationship helps the organisations to be more innovative and flexible in implementing SCRM initiatives. Having social trust in the relationship assists organisations to be more agile with regard to implementing SCRM. Six of the 21 participants indicated that agility is a way in which social trust improves SCRM in a buyer-supplier relationship. According to the literature, buyer-supplier relationships, where social trust is present, are capable of implementing SCRM initiatives more flexibly and effectively, which is mentioned in the findings above (Kim \& Choi 2015:63). The quotes below illustrate this point saliently:

'Whereas if they have a good relationship and there is trust, they know that it's happened in the past. We said that we will have it there first thing tomorrow, and we delivered on that. So they know that they can trust us. They'll say that's fine, as long as you have it there before this time. And so it works much better if you have their trust in place.' (P3, S2, Male, General Manager)

'But also what a high social relationship does is that it allows you to also think of creative ways. The guy might say, you know, I desperately need these five items. The other 10 I can wait for, just give me those five.' (P8, S7, Male, Chief Operating Officer)

The third and predominant way in which social trust helps to improve SCRM in a buyer-supplier relationship is through communication. Communication between a buyer and supplier organisation is improved through the presence of social trust in the relationship. Supply chain risk management is improved through the enhancement of communication between the buyer and supplier. The findings of the study signified that personal relationships need to be perceptible to improve SCRM in a buyer-supplier relationship. Nineteen of the 21 participants indicated that communication is an imperative way in which social trust improves SCRM in a buyer-supplier relationship. These findings support the literature, which states that social interactions are a strong building block of trust (Meyer et al. 2017:7). Refer to the exemplary quotes below:

'Having a level of personal relationship, where you know a little bit about the person and their life, I think that actually goes a long way to building a healthy trusting relationship.' (P13, B3, Female, Supply Chain Manager)

'Where because of the personal relations and the trust one can just pick up the phone and say it needs to happen and it does happen. Successful business partnering is first and foremost, but also interaction with people on a personal level is important. That is where you build and cement the trust.' (P18, B7, Male, Head of Transport)

Furthermore, two additional distinctive findings were made through conducting the study. The first one being the importance of trust being present in a buyer-supplier relationship in aiding the implementation of SCRM. This is beyond doubt apparent. Improved customer satisfaction and overall business performances are some of the benefits of having trust in a buyer-supplier relationship (Fawcett \& Waller 2013:3). These benefits cannot be attained without the successful implementation of SCRM, which is assisted by having a stable, trusting relationship. Throughout conducting the interviews, it was clearly indicated by all the participants that trust needs to be present in carrying out SCRM. This can be seen from the following quotes:

'But the trust factor is integral to the relationship of risk mitigation.' (P4, S3, Male, Business Development Executive)

'And if customers trust you, then yes, once again, they are going to collaborate with you to reduce risk.' (P6, S5, Male, Managing Director)

'So again they are both so closely interconnected. One without the other means nothing.' (P13, B3, Female, Supply Chain Manager)

The secondary findings indicated that organisations could not successfully implement SCRM independently. A supply chain network is affected as a whole by SCRs, and therefore 
organisations should not implement SCRM independently (Kwak et al. 2018:373). It is essential for organisations to collaborate with their supply chain partners to successfully implement SCRM in a buyer-supplier relationship. All participants indicated during the interviews that SCRM can only be implemented successfully if the parties do it collaboratively and not independently. This corroborates the literature, which indicates that organisations cannot implement SCRM successfully on their own (Kwak et al. 2018:373). Refer to the exemplary quotes below:

'Directly, they form an integral part of the risk management system, and they form an integral part of our risk matrix as well.' (P9, B1, Male, Logistics Manager)

'Yes 100\%, nothing actually happens here without O9 and nothing happens without $\mathrm{O} 18$, so it is a joint venture - 50/50. One cannot run without the other.' (P19, B8, Male, Customer Service Manager)

\section{Conclusions and theoretical implications}

The purpose of this generic qualitative study was to explore the taxonomies of trust in SCRM in buyer-supplier relationships within the South African 3PL industry. The study focused, in particular, upon four key constructs adopted from the TCC Model of Earle et al. (2010:6) and their role in trust in SCRM in a buyer-supplier relationship. Findings in response to the first research question revealed that having similar values in an organisation plays an important part in enhancing trust in a buyer-supplier relationship. There are four ways in which value similarity plays a role in SCRM in a buyer-supplier relationship, namely relationship building, transparency, information sharing and similar objectives. Relationship building, transparency and similar objectives were the constructs that were most apparent in the findings. This indicates that organisations regard openness and honesty as crucial values that need to be aligned to improve SCRM. All four of the constructs supported what was stated in the literature, and therefore this confirms that these four constructs of value similarity play a key role in improving SCRM.

Findings relating to the second research question indicate that the past performance of organisations on how they previously handled SCRs has a major influence upon enhancing trust in a buyer-supplier relationship. The role of past performance in improving SCRM can be seen in three ways, namely business knowledge, confidence in ability and same goals. More than half of all the participants indicated that each one of these three ways, respectively, plays a vital role in improving SCRM. This reiterates the findings, which state that organisations use past performance to establish confidence in the supply chain partners' ability to mitigate SCRs in the future.

The findings pertaining to the third research question revealed that risk perception of organisations played an integral part in enhancing the trust in the buyer-supplier relationship. The findings divulged that there are three ways in which risk perception plays a role in SCRM. The first two constructs, namely greater alignment and similar intentions, were most prominent in the findings with 16 of the 21 participants, indicating that these two concepts of risk perception play a vital role in improving SCRM. These two constructs indicate that when implementing SCRM, the alignment of objectives, as well as intentions, is of the utmost importance, to improve SCRM. The other concept, which was pointed out by only eight of the 21 participants, was reliability, which expands upon the existing literature. Greater alignment and similar intentions corroborate and confirm opinions raised in the literature.

The findings of the study corroborate the extant literature in three ways. Firstly, according to Friday et al. (2018:231), organisations attempting to perform SCRM benefit exponentially from continuously enhancing the trust present in a buyer-supplier relationship. This statement was confirmed by the findings of the study, which clearly indicate that trust is of immense value in the implementation of SCRM in a buyer-supplier relationship. Secondly, in accordance with Kwak et al. (2018:373), SCRM can rarely be implemented successfully independently. This was confirmed by the findings of the study, namely that SCRM cannot be implemented independently. Thirdly, for each main construct, the study presents three or four ways on how they play a role in improving SCRM. Each one of these concepts (sub-themes) supports and confirms statements made in the existing literature. Each of the main constructs presented at least one or two concepts that are more perceptible than the rest of the concepts. For value similarity, the most noticeable concept was transparency, which concurs with the literature in stating that openness and honesty are crucial for successful SCRM implementation (Cho et al. 2017:185). Past performance identified confidence in the ability of the supply chain partners to mitigate SCRs. This was the concept most apparent in the findings. This adds to the literature in indicating that the confidence in ability is the most important concept of past performance to improve SCRM (Wang et al. 2014:377).

Regarding risk perception, two equally important concepts were most noticeable in the findings: greater alignment and similar intentions. This confirms what was stated in the literature by pointing out the importance of aligning risk perceptions and working towards a unified objective when implementing SCRM (Kwak et al. 2018:373). Communication, a cornerstone of social trust, was the finding of paramount importance, and this was in alignment with the existing literature. Communication between a buyer and supplier organisation is improved with the presence of social trust in the relationship (Meyer et al. 2017:7). Through better communication, the implementation of SCRM is aided and improved.

\section{Managerial implications}

Firstly, managers should acknowledge the importance of having trust in their relationships with their 3PL partners. The study indicates that trust is of the utmost importance 
when implementing SCRM, especially with key suppliers such as 3PLs that play an orchestrating role between the buying organisation and their customers within their respective supply chain. Trust can be considered as an enabler of SCRM, and therefore managers should work upon establishing and maintaining trust in a buyer-supplier relationship. The study recommends that managers focus upon processes or strategies that may be implemented to improve trust in a buyer-supplier relationship, by value similarity, past performance, risk perception and social trust.

Secondly, the study indicates which of the specific concepts of each of the four main constructs should be prioritised when considering improvements in the trust in the relationship. The findings indicate which of the concepts under each main construct plays the particular leading role in improving SCRM in a buyer-supplier relationship. With value similarity, transparency plays the biggest role in improving SCRM in a buyer-supplier relationship. In the case of past performance, the confidence in ability plays the biggest role in improving SCRM. For risk perception, greater alignment and similar intentions play equally important leading roles in improving SCRM. Important to note is the fact that communication plays the biggest role in aiding social trust in the relationship and ultimately improving SCRM in a buyer-supplier relationship. Managers should shift their focus to concepts such as those listed above, in an attempt to improve the SCRM in their relationships.

\section{Limitations and directions for future research}

The study conducted interviews with the same number of buyer and supplier organisations, which yielded an equal volume of data. The present study only managed to involve eight dyadic relationships. A recommendation for future research is, therefore, to collect data only from dyadic buyersupplier relationships. Such a focus will provide two perspectives upon the same constructs in the same relationship. Investigating the similarities and differences arising from such a study would provide a more in-depth description of the research problem than the current study has been able to do. Furthermore, the current study only focused upon the four constructs proposed by the TCC Model of Earle et al. (2010:6). Therefore, the study's scope of taxonomies of trusts is limited as data were collected from a limited (cross-sectional) period. Future research may discover more constructs related to taxonomies of trust if the study is conducted from a longitudinal period. There might be other constructs, which this study did not address, and therefore further research should be conducted regarding the phenomenon. Lastly, the study was conducted from a qualitative research methodology. By applying a quantitative research methodology, a larger sample of participants from multiple industries may allow a greater generalisability of the findings of the study. This will also allow for a more rounded perspective of SCRM among supply chain practitioners. Because a qualitative approach was used, the findings cannot be generalised to other industries and sectors in South Africa. The findings are therefore applicable to the 3PL industry only.
A replication of this study can be conducted in other industries to increase the generalisability of the findings.

\section{Acknowledgements Competing interests}

The authors declare that they have no financial or personal relationships that may have inappropriately influenced them in writing this article.

\section{Authors' contributions}

G.U. collected the data of the research as part of his Master's degree. A.M. and W.N. acted as the supervisors of the research and prepared the article.

\section{Funding information}

This research received no specific grant from any funding agency in the public, commercial or not-for-profit sectors.

\section{Data availability statement}

Data sharing is available on request.

\section{Disclaimer}

The views and opinions expressed in this article are those of the authors and do not necessarily reflect the official policy or position of any affiliated agency of the authors.

\section{References}

Abeyratne, S.A. \& Monfared, R.P., 2016, 'Blockchain ready manufacturing supply chain using distributed ledger', International Journal of Research in Engineering and Technology 5(9), 1-10.

Akman, G. \& Baynal, K., 2014, 'Logistics service provider selection through an integrated fuzzy multicriteria decision making approach', Journal of Industrial Engineering 2014, 1-16. https://doi.org/10.1155/2014/794918

Alkhatib, S.F., Darlington, R. \& Nguyen, T.T., 2015, 'Logistics service providers (LSPs) evaluation and selection: Literature review and framework development', Strategic Outsourcing: An International Journal 8(1), 102-134. https://doi. org/10.1108/SO-12-2014-0028

Armstrong \& Associates, 2017, Global 3PL market size estimates, viewed 01 May 2018, from http://www.3plogistics.com/3pl-market-info-resources/3pl-marketinformation/global-3pl-market-size-estimates/.

Barnes, B.R., Leonidou, L.C., Siu, N.Y. \& Leonidou, C.N., 2015, 'Interpersonal factors as drivers of quality and performance in Western-Hong Kong interorganizational business relationships', Journal of International Marketing 23(1), 23-49.

Brandon-Jones, E., Squire, B., Autry, C.W. \& Petersen, K.J., 2014, 'A contingent resource-based perspective of supply chain resilience and robustness', Journal of Supply Chain Management 50(3), 55-73. https://doi.org/10.1111/jscm.12050

Branyi, A., Jozsa, L. \& Machova, R., 2015, 'The role of social capital elements: Hungarian winery networks case study', National Academy of Management 2015(8), 100-110.

Braun, V. \& Clarke, V., 2012, 'Thematic analysis', in H. Cooper (ed.), APA handbook of research methods in psychology: vol. 2 Research designs, American Psychological Association, Washington, DC.

Bühler, A., Wallenburg, C.M. \& Wieland, A., 2016, 'Accounting for external turbulence of logistics organizations via performance measurement systems', Supply Chain Management: An International Journal 21(6), 694-708. https://doi.org/10.1108/ SCM-02-2016-0040

Capaldo, A. \& Giannoccaro, I., 2015, 'How does trust affect performance in the supply chain? The moderating role of interdependence', International Journal of Production Economics 166, 36-49. https://doi.org/10.1016/j.ijpe.2015.04.008

Chang, W., Ellinger, A.E. \& Blackhurst, J., 2015, 'A contextual approach to supply chain risk mitigation', The International Journal of Logistics Management 26(3), 642-656. https://doi.org/10.1108/IJLM-02-2014-0026

Charkhab, H.K., Eslami, S. \& Dehnavi, H.D., 2014, 'Linking risk management practices and strategies to performance: Case study: Ceramic and tiles industry', Internafional Journal of Academic Research in Accounfing, Finance and Management Sciences 4(2), 417-428. 
Charmaz, K., 2006, Constructing grounded theory: A practical guide through qualitative analysis, Sage, Newbury Park, CA.

Chen, P.Y., Chen, K.Y. \& Wu, L.Y., 2017, 'The impact of trust and commitment on value creation in asymmetric buyer-seller relationships: The mediation effect of specific asset investments', Journal of Business \& Industrial Marketing 32(3), 457-471. https://doi.org/10.1108/JBIM-09-2014-0171

Chi, M., Zhao, J. \& George, J.F., 2015, 'Mediation and time-lag analyses of e-alignment and e-collaboration capabilities', Industrial Management \& Data Systems 115(6), 1113-1131. https://doi.org/10.1108/IMDS-01-2015-0016

Cho, B., Ryoo, S.Y. \& Kim, K.K., 2017, 'Interorganizational dependence, information transparency in interorganizational information systems, and supply chain performance', European Journal of Information Systems 26(2), 185-205. https:// doi.org/10.1057/s41303-017-0038-1

Chung, H.F., Wang, C.L., Huang, P.-h. \& Yang, Z., 2016, 'Organizational capabilities and business performance: When and how does the dark side of managerial tie matter?', Industrial Marketing Management 55, 70-82. https://doi.org/10.1057/ s41303-017-0038-1

Coyle, J.J., Langley, C.J., Novack, R.A. \& Gibson, B., 2017, Supply chain management: A logistics perspective, 10th edn., Cengage Learning, Boston, MA.

Creswell, J.W., 2012, Educational research: Planning, conducting, and evaluating quantitative and qualitative research, 4 th edn., Pearson, Boston, MA.

D’Amato, A.A., Kgoedi, S., Swanepoel, G., Walters, J., Drotskie, A. \& Kilbourn, P.J., 2015, 'Convergence of logistics planning and execution in outsourcing: Original research', Journal of Transport and Supply Chain Management 9(1), 1-9. https:// research', Journal of Transport and
doi.org/10.4102/jtscm.v9i1.159

Dong, Q. \& Cooper, O., 2016, 'An orders-of-magnitude AHP supply chain risk assessment framework', International Journal of Production Economics 182, 144-156. https://doi.org/10.1016/j.ijpe.2016.08.021

Earle, T.C., Siegrist, M. \& Gutscher, H., 2010, Trust in risk management: Uncertainty and scepticism in the public mind, Earthscan, London.

Elleuch, H., Hachicha, W. \& Chabchoub, H., 2014, 'A combined approach for supply chain risk management: Description and application to a real hospital pharmaceutical case study', Journal of Risk Research 17(5), 641-663. https://doi. org/10.1080/13669877.2013.815653

Fan, H., Li, G., Sun, H. \& Cheng, T., 2017, 'An information processing perspective on supply chain risk management: Antecedents, mechanism, and consequences', International Journal of Production Economics 185, 63-75. https://doi. org/10.1016/j.ijpe.2016.11.015

Fan, Y. \& Stevenson, M., 2018, 'A review of supply chain risk management: Definition, theory, and research agenda', International Journal of Physical Distribution \& Logistics Management 48(3), 1-28. https://doi.org/10.1108/ IJPDLM-01-2017-0043

Fawcett, S.E. \& Waller, M.A., 2013, 'Inquiry and the practice of theoretical conversation: Engaging in dialogue to elaborate hidden connections', Journal of Business Logistics 34(1), 1-5. https://doi.org/10.1111/jbl.12005

Friday, D., Ryan, S., Sridharan, R. \& Collins, D., 2018, 'Collaborative risk management: A systematic literature review', International Journal of Physical Distribution \& Logistics Management 48(3), 231-253. https://doi.org/10.1108/IJPDLM-012017-0035

Ghadge, A., Dani, S., Ojha, R. \& Caldwell, N., 2017, 'Using risk sharing contracts for supply chain risk mitigation: A buyer-supplier power and dependence perspective', supply chain risk mitigation: A buyer-supplier power and dependence perspective,
Computers \& Industrial Engineering 103, 262-270. https://doi.org/10.1016/j. computers \& In

Gligor, D.M. \& Esmark, C.L., 2015, 'Supply chain friends: The good, the bad, and the ugly', Business Horizons 58(5), 517-525. https://doi.org/10.1016/j.bushor. ugly', Business

Gligor, D.M. \& Holcomb, M., 2013, 'The role of personal relationships in supply chains: An exploration of buyers and suppliers of logistics services', The International Journal of Logistics Management 24(3), 328-355. https://doi.org/10.1108/IJLM07-2012-0067

Grötsch, V.M., Blome, C. \& Schleper, M.C., 2013, 'Antecedents of proactive supply chain risk management - A contingency theory perspective', International Journa of Production Research 51(10), 2842-2867. https://doi.org/10.1080/00207543. 2012.746796

Handfield, R.B., Cousins, P.D., Lawson, B. \& Petersen, K.J., 2015, 'How can supply management really improve performance? A knowledge-based model of alignment capabilities', Journal of Supply Chain Management 51(3), 3-17. https:// doi.org/10.1111/jscm.12066

Heiyantuduwa, M., Wannisingha, W.M.N.N. \& Rupasinghe, T., 2015, 'A strategic analysis of the use of Third Party Logistics Providers (3PLS) in Fast Moving Consumer Goods (FMCG) Industry: A systematic review of literature', in 12th International Conference on Business Management (ICBM), December 7 , 2015. Ho, W., Zheng, T., Yildiz, H. \& Talluri, S., 2015, 'Supply chain risk management:
A literature review', International Journal of Production Research 53(16), 5031-5069. https://doi.org/10.1080/00207543.2015.1030467

Hudnurkar, M., Rathod, U. \& Jakhar, S.K., 2016, 'Multi-criteria decision framework for supplier classification in collaborative supply chains: Buyer's perspective', International Journal of Productivity and Performance Management 65(5), 622-640. https://doi.org/10.1108/IJPPM-03-2015-0048

Huo, B., Zhang, C. \& Zhao, X., 2015, 'The effect of IT and relationship commitment on supply chain coordination: A contingency and configuration approach', Information \& Management 52(6), 728-740. https://doi.org/10.1016/j.im.2015.06.007

Jayaram, J. \& Tan, K.C., 2010, 'Supply chain integration with third-party logistics providers', International Journal of Production Economics 125(2), 262-271.
Jüttner, U., 2005, 'Supply chain risk management: Understanding the business requirements from a practitioner perspective', The International Journal of requirements from a practitioner perspective, The International Journal of
Logistics Management 16(1), 120-141. https://doi.org/10.1108/09574090510 617385

Kilubi, I. \& Haasis, H., 2015, 'Supply chain risk management enablers - a framework development through systematic review of the literature from 2000 to 2015', International Journal of Business Science and Applied Management 10(1), 35-54.

Kim, Y. \& Choi, T.Y., 2015, 'Deep, sticky, transient, and gracious: An expanded buyersupplier relationship typology', Journal of Supply Chain Management 51(3), 61-86. https://doi.org/10.1111/jscm.12081

König, A. \& Spinler, S., 2016, 'The effect of logistics outsourcing on the supply chain vulnerability of shippers: Development of a conceptual risk management framework', The International Journal of Logistics Management 27(1), 122-141. https://doi.org/10.1108/IJLM-03-2014-0043

Kumar, R.S., Choudhary, A., Babu, S.A.I., Kumar, S.K., Goswami, A. \& Tiwari, M.K. 2017, 'Designing multi-period supply chain network considering risk and emission: A multi-objective approach', Annals of Operations Research 250(2), 427-461.

Kumar Sharma, S. \& Bhat, A., 2014, 'Supply chain risk management dimensions in Indian automobile industry: A cluster analysis approach', Benchmarking: An International Journal 21(6), 1023-1040. https://doi.org/10.1108/BIJ-02 2013-0023

Kwak, D.-W., Rodrigues, V.S., Mason, R., Pettit, S. \& Beresford, A., 2018, 'Risk interaction identification in international supply chain logistics: Developing a holistic model', International Journal of Operations \& Production Management 38(2), 372-389. https://doi.org/10.1108/IJOPM-03-2016-0121

Li, G., Fan, H., Lee, P.K. \& Cheng, T., 2015, 'Joint supply chain risk management: An agency and collaboration perspective', International Journal of Production Economics 164, 83-94. https://doi.org/10.1016/j.ijpe.2015.02.021

Li, Z., De Souza, R. \& Goh, M., 2016, 'Supply chain orchestration leveraging on MNC networks and local resources: Approach strategies', Journal of Service Science and Management 9(4), 303-319. https://doi.org/10.4236/jssm.2016.94036

Lord, N., Spencer, J., Albanese, J. \& Elizondo, C.F., 2017, 'In pursuit of food system integrity: The situational prevention of food fraud enterprise', European Journa on Criminal Policy and Research 23(4), 483-501. https://doi.org/10.1007/s10610017-9352-3

Macdonald, J.R. \& Corsi, T.M., 2013, 'Supply chain disruption management: Severe events, recovery, and performance', Journal of Business Logistics 34(4), 270-288. https://doi.org/10.1111/jbl.12026

Maestrini, V., Caniato, F., Martinez, V., Neely, A., Luzzini, D. \& Maccarrone, P., 2018 'The relationship regulator: A buyer-supplier collaborative performance measurement system', International Journal of Operations and Production Management 38(11), 1-20. https://doi.org/10.1108/IJOPM-10-2016-0595

Merriam, S.B., 2009. Qualitative research: A guide to design and implementation, Jossey-Bass, San Fransisco, CA.

Meyer, A., Niemann, W. \& Kotzé, T., 2017, 'Exploring the dark side of interpersonal relationships between buyers and suppliers of logistics services', Acta Commercii 17(1), 1-12. https://doi.org/10.4102/ac.v17i1.437

Mocke, K., Niemann, W. \& Kotzé, T. 2016, 'The role of personal relationships between buyers and suppliers of third-party logistics services: A South African perspective, Acta Commercii 16(1), 1-13. https://doi.org/10.4102/ac.v16i1.367

Moore, N.Y., Loredo, E.N., Cox, A.G. \& Grammich, C.A., 2015, Identifying and managing acquisition and sustainment supply chain risks, Rand Cooperation, Santa Monica, CA, viewed 03 May 2018, from http://www.dtic.mil/docs/ Santa Monica, CA, viev
citations/ADA617799.

Nooraie, S.V. \& Parast, M.M., 2015, 'A multi-objective approach to supply chain risk management: Integrating visibility with supply and demand risk', International Journal of Production Economics 161, 192-200. https://doi.org/10.1016/j. Journal of Prod
ijpe.2014.12.024

Niemann, W., Meyer, A., Kotzé, T., Odendaal, J., 2018, 'The role of third party logistics providers as orchestrators in emerging markets', International Business Conference (IBC) 12th Annual Conference, Mauritius, 23th to 26th September 2018.

Nyaga, G.N., Whipple, J.M. \& Lynch, D.F., 2010, 'Examining supply chain relationships: Do buyer and supplier perspectives on collaborative relationships differ?', Journal of Operations Management 28(2), 101-114. https://doi.org/10.1016/j.jom. 2009.07.005

Ojha, D., Shockley, J. \& Acharya, C., 2016, 'Supply chain organizational infrastructure for promoting entrepreneurial emphasis and innovativeness: The role of trust and learning', International Journal of Production Economics 179, 212-227. https:// doi.org/10.1016/j.ijpe.2016.06.011

Palinkas, L.A., Horwitz, S.M., Green, C.A., Wisdom, J.P., Duan, N. \& Hoagwood, K., 2015, 'Purposeful sampling for qualitative data collection and analysis in mixed method implementation research', Administration and Policy in Mental Health and Mental Health Services Research 42(5), 533-544. https://doi.org/10.1007/ s10488-013-0528-y

Patton, M.Q., 2015. Qualitative research \& evaluation methods: Integrating theory and practice. 4th edn., Sage, Thousand Oaks, CA.

Percy, W.H., Kostere, K. \& Kostere, S., 2015, 'Generic qualitative research in psychology', Qualitative Report 20(2), 76-85.

Plano Clark, V.L. \& Creswell, J.W., 2015. Understanding research: A consumer's guide, 2nd edn., Pearson Education, Boston, MA.

Polit, D.F. \& Beck, C.T., 2012. Nursing research: Generating and assessing evidence for nursing practice, 9th edn., Lippincott Williams \& Wilkins, Philadelphia, PA. 
Prakash, S., Soni, G. \& Rathore, A.P.S., 2017, 'A critical analysis of supply chain risk management content: A structured literature review', Journal of Advances in Management Research 14(1), 69-90. https://doi.org/10.1108/JAMR-10 in Managem

Qazi, A., Dickson, A., Quigley, J. \& Gaudenzi, B., 2018, 'Supply chain risk network management: A Bayesian belief network and expected utility based approach for managing supply chain risks', International Journal of Production Economics 196, 24-42. https://doi.org/10.1016/j.ijpe.2017.11.008

Qu, W.G., Pinsonneault, A., Tomiuk, D., Wang, S. \& Liu, Y., 2015, 'The impacts of social trust on open and closed B2B e-commerce: A Europe-based study' Information \& Management 52(2), 151-159. https://doi.org/10.1016/j. im.2014.07.002

Ramanathan, U. \& Gunasekaran, A., 2014, 'Supply chain collaboration: Impact of success in long-term partnerships', International Journal of Production Economics 147, 252-259. https://doi.org/10.1016/j.ijpe.2012.06.002

Rashid, A.H.M., Loke, S.-P. \& Ooi, K.-B., 2014, 'Strengthening supply chain risk management for business continuity: A case study approach', International Journal of Management and Enterprise Development 13(3-4), 278-301. https:// doi.org/10.1504/IJMED.2014.069173

Revilla, E. \& Saenz, M.J., 2017, 'The impact of risk management on the frequency of supply chain disruptions: A configurational approach', International Journal of Operations \& Production Management 37(5), 557-576. https://doi.org/10.1108/ IJOPM-03-2016-0129

Riley, J.M., Klein, R., Miller, J. \& Sridharan, V., 2016, 'How internal integration information sharing, and training affect supply chain risk management capabilities', International Journal of Physical Distribution \& Logistics Managemen 46(10), 953-980. https://doi.org/10.1108/IJPDLM-10-2015-0246

Ryciuk, U., 2017, 'Identification of factors related to trust formation in construction supply chains', Procedia Engineering 182, 627-634. https://doi.org/10.1016/j proeng.2017.03.168

Sahu, A.K., Datta, S. \& Mahapatra, S., 2017, 'Evaluation of performance index in resilient supply chain: A fuzzy-based approach', Benchmarking: An International Journal 24(1), 118-142. https://doi.org/10.1108/BIJ-07-2015-0068

Saunders, M., Lewis, P. \& Thornhill, A., 2016, Research methods for business students, 7 th edn., Pearson, Essex.

Shenton, A.K., 2004, 'Strategies for ensuring trustworthiness in qualitative research projects', Education for Information 22(2), 63-75. https://doi.org/10.3233/efi2004-22201

Simba, S., Niemann, W., Kotzé, T. \& Agigi, A., 2017, 'Supply chain risk management processes for resilience: A study of South African grocery manufacturers', Journal of Transport and Supply Chain Management 11(1), 1-13. https://doi.org/10.4102/ jtscm.v11i0.325

Slovic, P., 1993, 'Perceived risk, trust, and democracy', Risk analysis 13(6), 675-682. https://doi.org/10.1111/j.1539-6924.1993.tb01329.x

Soosay, C.A. \& Hyland, P., 2015, 'A decade of supply chain collaboration and directions for future research', Supply Chain Management: An International Journal 20(6) 613-630. https://doi.org/10.1108/SCM-06-2015-0217

Spence, M., Stancu, V., Elliott, C.T. \& Dean, M., 2018, 'Exploring consumer purchase intentions towards traceable minced beef and beef steak using the theory of planned behavior', Food Control 91, 138-147. https://doi.org/10.1016/j. foodcont.2018.03.035
Tejpal, G., Garg, R. \& Sachdeva, A., 2013, 'Trust among supply chain partners: A review', Measuring Business Excellence 17(1), 51-71. https://doi.org/10.1108/ 13683041311311365

Thomas, S., Eastman, J., Shepherd, C.D. \& Denton, L.T., 2018, 'A comparative assessment of win-win and win-lose negotiation strategy use on supply chain relational outcomes', International Journal of Logistics Management 29(1) 191-215. https://doi.org/10.1108/IJLM-10-2016-0238

Trkman, P., Oliveira, M.P.V.D. \& McCormack, K., 2016, 'Value-oriented supply chain risk management: You get what you expect', Industrial Management \& Data System 116(5), 1061-1083. https://doi.org/10.1108/IMDS-09-2015-0368

University of Stellenbosch, 2016, Logistics barometer South Africa 2016, viewed 01 June 2018, from https://www.sun.ac.za/english/faculty/economy/logistics/ Documents/Logistics\%20Barometer/Logistics\%20Barometer\%202016\%20 Report.pdf.

Vaismoradi, M., Turunen, H. \& Bondas, T., 2013, 'Content analysis and thematic analysis: Implications for conducting a qualitative descriptive study', Nursing \& Health Sciences 15(3), 398-405. https://doi.org/10.1108/IMDS-09-2015-0368

Van Riper, C.J., Wallen, K.E., Landon, A.C., Petriello, M.A., Kyle, G.T. \& Absher, J., 2016 'Modeling the trust-risk relationship in a wildland recreation setting: A socia exchange perspective', Journal of Outdoor Recreation and Tourism 13, 23-33. https://doi.org/10.1016/j.jort.2015.11.001

Villena, V.H., Revilla, E. \& Choi, T.Y., 2011, 'The dark side of buyer-supplier relationships: A social capital perspective', Journal of Operations management 29(6), 561-576. https://doi.org/10.1016/j.jom.2010.09.001

Wandfluh, M., Hofmann, E. \& Schoensleben, P., 2016, 'Financing buyer-supplier dyads: An empirical analysis on financial collaboration in the supply chain', International Journal of Logistics Research and Applications 19(3), 200-217. https://doi.org/10.1080/13675567.2015.1065803

Wang, B., Childerhouse, P., Kang, Y., Huo, B. \& Mathrani, S., 2016, 'Enablers of supply chain integration: Interpersonal and interorganizational relationship perspectives', Industrial Management \& Data Systems 116(4), 838-855. https://doi.org/ 10.1016/j.jom.2010.09.001

Wang, Q., Craighead, C.W. \& Li, J.J., 2014, 'Justice served: Mitigating damaged trust stemming from supply chain disruptions', Journal of Operations Management 32(6), 374-386. https://doi.org/10.1016/j.jom.2014.07.001

Wieland, A. \& Wallenburg, C.M., 2013, 'The influence of relational competencies on supply chain resilience: A relational view', International Journal of Physical Distribution \& Logistics Management43(4),300-320. https://doi.org/10.1108/IJPDLM-08-2012-0243

Wu, I.-L., Chuang, C.-H. \& Hsu, C.-H., 2014, 'Information sharing and collaborative behaviors in enabling supply chain performance: A social exchange perspective' International Journal of Production Economics 148, 122-132. https://doi. org/10.1016/j.ijpe.2013.09.016

Yan, Z., Zhang, P. \& Vasilakos, A.V., 2014, 'A survey on trust management for internet of things', Journal of Network and Computer Applications 42, 120-134. https:// doi.org/10.1016/j.jnca.2014.01.014

Yang, J., 2014, 'Supply chain agility: Securing performance for Chinese manufacturers', International Journal of Production Economics 150, 104-113. https://doi. org/10.1016/j.ijpe.2013.12.018

Zhu, W., Ng, S.C., Wang, Z. \& Zhao, X., 2017, 'The role of outsourcing management process in improving the effectiveness of logistics outsourcing', International Journal of Production Economics 188, 29-40. https://doi.org/10.1016/j.ijpe.2017.03.004 